\title{
Factors Affecting Subjective and Objective Outcomes and Return to Play in Anterior Cruciate Ligament Reconstruction: A Retrospective Cohort Study
}

\author{
Federica Rosso ${ }^{1}$ Davide E. Bonasia ${ }^{1} \quad$ Umberto Cottino $^{1} \quad$ Simone Cambursano $^{2}$ Federico Dettoni ${ }^{1}$ \\ Roberto Rossi ${ }^{1}$ \\ ${ }^{1}$ Department of Orthopaedics and Traumatology, AO Ordine \\ Mauriziano Hospital, Turin, Italy \\ 2 Department of Orthopedics and Traumatology, University of Turin, \\ Turin, Italy \\ Address for correspondence Federica Rosso, MD, Department of \\ Orthopaedics and Traumatology, AO Ordine Mauriziano Hospital, \\ Largo Turati 62, Turin 10128, Italy (e-mail: federica.rosso@yahoo.it). \\ Joints 2018;6:23-32.
}

\begin{abstract}
Keywords

- knee

- anterior cruciate ligament

- reconstruction

- instability

- athlete
\end{abstract}

Purpose To analyze the prognostic factors influencing subjective and objective outcomes and return to play (RTP) after anterior cruciate ligament reconstruction (ACL-R).

Methods Primary ACL-Rs using a transtibial technique performed between 2008 and 2012 were included. Data regarding patients, surgery, sports, and rehabilitation, including an on-field rehabilitation (OFR) and duration of the rehabilitation program, were collected. The International Knee Documentation Committee (IKDC) subjective and objective evaluation forms, and the Knee Injury and Osteoarthritis Outcome Score and Lysholm questionnaires were used for the assessment of subjective and objective outcomes. The Subjective Patient Outcome for Return to Sports and ACL-return to sport after injury (RSI) scores were used for RTP evaluation. Several potential predictors of outcome were tested with a univariate analysis. All the variables with $p<0.1$ were retested in a logistic regression model to evaluate their association with the outcomes. Results In total, 176 cases were included with an average follow-up of 44.1 months. Of the patients, $92.2 \%$ were rated as normal or nearly normal at the IKDC evaluation. In addition, $90.1 \%$ of the patients returned to sport, with $57.6 \%$ returning to the same preinjury level. Objective outcomes were negatively influenced by late rehabilitation (odds ratio $[O R]=2.75$ ). Performing an OFR phase during the rehabilitation was associated with better subjective outcomes $(O R=2.71)$. Length of rehabilitation strongly influenced the RTP rate $(O R=13.16)$. Conversely, higher ACL-RSI score was inversely related to RTP. Objective IKDC score was inversely related to the ACL-RSI $(\mathrm{OR}=0.31)$, whereas subjective score was correlated with both the total ACL-RSI score $(\mathrm{OR}=0.15)$ and the level of activity $(\mathrm{OR}=0.20)$.

Conclusion This study confirmed the role of rehabilitation on subjective and objective outcomes and on RTP. Particularly, the complete adherence to a rehabilitation program, including an OFR phase, resulted in better subjective outcomes and higher RTP rate. The relationship between psychological factors, measured through the ACLRSI score, and RTP was confirmed.

Level of Evidence Level III, observational study without a control group. published online March 7, 2018
DOI https://doi.org/ 10.1055/s-0038-1636931. ISSN 2282-4324.
Copyright (c) 2018 Georg Thieme Verlag License terms KG Stuttgart · New York

() (1) $\odot \circledast$ 


\section{Introduction}

Anterior cruciate ligament $(\mathrm{ACL})$ tear is a common injury in athletes. It has been estimated that the number of $\mathrm{ACL}$ reconstructions (ACL-Rs) in the United States rose from 32.9/ 100,000 person-years in 1994 to $43.5 / 10,000$ person-years in 2006. Furthermore, the incidence of ACL-R increased particularly in female patients younger than 20 years or older than 40 years. ${ }^{1}$ Different studies reported good subjective and objective outcomes after ACL-R, with satisfactory results in 75 to $97 \%$ of the patients, but there is still 10 to $15 \%$ of failure rate. $^{2}$ There is some agreement in literature defining the return-to-play (RTP) rate as an important outcome measure of ACL-R, especially in athletes. Different authors concluded that less than $50 \%$ of the patients returned to play sports at the preinjury level at a 7-year follow-up. ${ }^{3,4}$ Ardern et al. in a recent systematic review reported that $81 \%$ of the patients returned to play sports, $65 \%$ returned to their preinjury level, and $55 \%$ returned to competitive level sports after surgery. ${ }^{5}$ Nwachukwu et al reported an $87 \%$ of RTP rate after ACL-R, with $89.1 \%$ of the patients returning to prior level of competition. ${ }^{6}$ In a recent meta-analysis, Lai et al concluded that $83 \%$ of elite athletes returned to sports following ACL-R. ${ }^{7}$

Several authors evaluated the factors associated with return to sports activity. ${ }^{8,9}$ The importance of psychological response and fear of reinjury (kinesophobia) after ACL-R has been also recently underlined. ${ }^{10-12}$ Paterno et al, in their retrospective study on $40 \mathrm{ACL}-\mathrm{Rs}$, concluded that patients with greater fear of reinjury were four times more likely to gain lower level of activity, seven times more likely to have a single-hop limb asymmetry, and six times more likely to have a deficit of quadriceps strength greater than $90 \%$ compared with the contralateral limb. ${ }^{13}$

A new scale called ACL-return to sports after injury (ACLRSI) score was developed to better evaluate psychological impact of returning to sport after ACL-R. ${ }^{14}$ This scale analyzes three types of psychological responses believed to be associated with RTP (emotions, confidence in performance, and risk appraisal). ${ }^{14}$ Müller et al, in their prospective study, confirmed that the ACL-RSI was significantly lower in patients who did not resume previous activities compared with "returned-to-sport" patients. ${ }^{15}$ Furthermore, different studies confirmed the importance of rehabilitation, particularly adding a phase of on-field rehabilitation (OFR) at the end of the program, in improving RTP, especially in soccer players. ${ }^{16}$ This is probably due to an increased athlete's confidence and a better sport-specific rehabilitation. Other authors evaluated the possible patient or surgery-related factors associated with outcomes, such as obesity, smoking, cartilage degeneration, meniscal status, type of graft, and kinesophobia. ${ }^{10,17-20}$ Despite the amount of literature regarding ACL-R outcomes and prognostic factors, few papers focused contemporarily on the patient and surgery-related factors influencing subjective and objective outcomes and on their role on RTP in both highand low-level athletes.

The aim of this study was to analyze factors related to subjective and objective outcomes and their association with RTP after ACL-R. The hypothesis of the study was that some factors significantly affect subjective and objective outcomes and RTP after ACL-R.

\section{Methods}

\section{Study Design}

The Institutional Review Board (IRB) at the author's institution defined this study as exempt from IRB approval (observational analytic study with a retrospective design on a wellestablished surgical procedure without a control group).

\section{Participants}

All the patients who underwent primary ACL-Rs using a transtibial technique by the same surgeon (R. R.) at our institution between January 2008 and December 2012 were included. Patients were evaluated, and data from surgery, sport participation, and rehabilitation were collected (-Table 1). Furthermore, data regarding complications, such as fever, wound's problems, and thrombotic events, and revision surgeries were recorded.

\section{Intervention}

All surgical procedures were single-incision arthroscopically assisted transtibial ACL-Rs. Patients received either quadrupled hamstrings (QHs) or a bone-patellar tendon-bone (BPTB) graft, depending on the surgeon's preference. In all the cases in which a $\mathrm{QH}$ was used, tibial fixation was performed with an interference screw and femoral one using cortical fixation button (Endobutton, Smith \& Nephew, Andover, Massachusetts, United States). When the BPTB graft was used, both femoral and tibial graft fixations were achieved with interference screws. Weight-bearing was allowed from the first postoperative day in all patients who underwent isolated ACL$\mathrm{R}$ or associated with partial meniscectomy. When a meniscal suture or cartilage procedure was performed, the postoperative protocol included a restriction of weight-bearing, depending on the associated procedures, for at least 4 weeks. Straightline running was allowed at an average of 12 weeks and sportspecific drills were allowed at an average of 16 to 20 weeks. Return to full sports participation was allowed, depending on the type and level of sports activity, between 6 and 9 months postoperatively. The criterion used to allow RTP were clinical knee stability, no pain or effusion, and satisfying functional testing (isokinetic test at least $85 \%$ compared with the contralateral side, and single-limb hop test greater than $90 \%$ compared with the contralateral side), as described in the literature. ${ }^{21,22}$ Single-limb hop test was used as a functional test, and a single hop for distance was applied. ${ }^{9,23}$ The isokinetic test was performed, according to previous studies, at a velocity of 60,180 , and 300 degrees per second with 5,10 , and 10 maximal concentric repetitions for flexion and extension, respectively. ${ }^{24}$

\section{Outcome Measures}

Four main outcome categories were identified: objective, subjective, sports activity, and failure.

The International Knee Documentation Committee (IKDC) objective knee evaluation form was used for the clinical 
Table 1 Detailed description of outcomes and predictor variables

\begin{tabular}{|c|c|}
\hline Outcome measures & Subgroups \\
\hline Objective outcomes & $\begin{array}{l}\text { Total IKDC (C-D) } \\
\text { Positive Pivot shift (B-C-D) } \\
\text { Positive Lachman (B-C-D) } \\
\text { Anterior crackling (B-C-D) } \\
\text { Leg hop test (B-C-D) }\end{array}$ \\
\hline Subjective outcomes & $\begin{array}{l}\text { Lysholm }>85 \text { points } \\
\text { IKDC }>78 \text { points } \\
\text { Knee function }>85 \%\end{array}$ \\
\hline Sport & $\begin{array}{l}\text { Return-to-sport (yes) } \\
\text { SPORTS score }(9-10) \\
\text { ACL-RSI > } 60 \%\end{array}$ \\
\hline Failure & $\begin{array}{l}\text { Revision ACL surgery (yes/ } \\
\text { no) }\end{array}$ \\
\hline Predictor variables & Variable \\
\hline Patient-related & $\begin{array}{l}\text { Age } \\
\text { Gender } \\
\text { Ipsilateral previous knee } \\
\text { surgery (yes/no) } \\
\text { Contralateral ACL recon- } \\
\text { struction (yes/no) }\end{array}$ \\
\hline Surgery-related & $\begin{array}{l}\text { Timing of surgery (acute: } \\
\text { within } 3 \text { mo) } \\
\text { Graft choice (BPTB vs. QH) } \\
\text { Associated procedures (yes/ } \\
\text { no) }\end{array}$ \\
\hline Rehabilitation-related & $\begin{array}{l}\text { Beginning of rehabilitation } \\
\text { (within or after } 1 \text { mo post- } \\
\text { operatively) } \\
\text { Duration of rehabilitation } \\
\text { (more or less than } 3 \text { mo) } \\
\text { Number of rehabilitation } \\
\text { sessions } \\
\text { On-field rehabilitation phase } \\
\text { (yes/no) }\end{array}$ \\
\hline Sport-related & Preoperative activity level \\
\hline Outcome-related & $\begin{array}{l}\text { Lysholm score }>85 \text { points } \\
\text { Total objective IKDC graded } \\
\text { as "A or B" } \\
\text { KT-1000 graded as "A or B" } \\
\text { ACL-RSI > } 60 \%\end{array}$ \\
\hline
\end{tabular}

Abbreviations: ACL-RSI, anterior cruciate ligament-return to sport after injury; BPTB, bone-patellar tendon-bone; IKDC, International Knee Documentation Committee; QH, quadrupled hamstrings; SPORTS, Subjective Patient Outcome for Return to Sports.

objective evaluation. ${ }^{25,26}$ Satisfactory knee function was defined as an overall classification of normal or nearly normal (categories A and B, respectively).

Patients were administered three validated self-reported questionnaires for subjective evaluation: the Knee Injury and Osteoarthritis Outcome Score, the Lysholm score, and the IKDC subjective evaluation form. ${ }^{27-31}$ Patients were also asked to rate their operated knee function with a percentage compared with the preinjury status. A good subjective outcome was defined as a Lysholm score higher than 85 points, satisfaction higher than $85 \%$, and IKDC score higher than 78 points. These cutoff values were chosen based on the available literature and the average value of this population. ${ }^{32}$ Particularly, Lysholm score was previously demonstrated to have a strong correlation with patient satisfaction, ${ }^{33}$ and the IKDC subjective knee score was reported in many different studies as a good outcome measurement in ACL-reconstructed patients. ${ }^{34,35}$

RTP was defined as returning to either practice or competition. For the RTP evaluation, patients completed a selfreported questionnaire with data regarding the sport played before injury, the activity level of competition (based on the Tegner ${ }^{27}$ questionnaire and divided into professional or not), and the postoperative activity level. Patients who did not resume sports at all or at the same preinjury level were asked to indicate the main reason. The causes were classified into knee-related (pain, instability, etc.) and personal (fear of reinjury, family, work, etc.). The Subjective Patient Outcome for Return to Sports (SPORTS) score was used to evaluate the level of sports participation compared with the preinjury period. ${ }^{36}$ The psychological involvement in both RTP and noRTP patients was assessed with the ACL-ACL-RSI score. ${ }^{14}$ This score consists of 12 questions for the evaluation of the three types of psychological responses believed to be associated with RTP (emotions, confidence in performance, and risk appraisal). A low ACL-RSI score is associated with low confidence in sport practice and high psychological involvement.

Some outcome measures (Lysholm score, total IKDC score, KT-1000 test, and ACL-RSI score) were also handled as potential prognostic factors affecting both RTP and SPORTS score and were defined as "outcome-related" predictor variables.

All the predictor and outcome variables were dichotomized. The cutoff for the different outcomes was based on literature data ${ }^{32}$ or on the average score obtained in this case series (-Table $\mathbf{1}$ ).

\section{Data Analysis}

Descriptive statistics was used for all demographics, subjective outcomes, sports participation, and rehabilitation data. Data were collected using Excel Microsoft. Continuous variables were expressed as mean, standard deviation (SD), and range. Student's $t$-test was applied to normally distributed continuous outcomes, whereas chi-square test was used for categorical outcomes to analyze differences between preoperative and postoperatively scores or data.

All the predictor variables were tested using a univariate logistic regression analysis to evaluate association with outcomes. Variables that showed $p$-value $>0.1$ at univariate analysis were removed from further statistical analysis to reduce the overfitting phenomenon. All the remaining variables were retested for each outcome using a multiple logistic regression, after the overall model fit analysis using the Medcalc (Ostend, Belgium) software, to evaluate their correlation with the outcomes.

\section{Results}

In total, 174 patients (176 knees) were included in the study, with an average follow-up of 44.1 months $(S D \pm 17.8$; range: 
11.8-75.9). There were 141 (80.1\%) men and 35 (19.9\%) women, with an average age of 29.5 years (SD \pm 9.6 years; range: $15-55)$. Of the patients, 116 were available for a clinical evaluation, whereas 60 (34.1\%) could not be clinically evaluated because they were unable to come for the follow-up visit. These patients were excluded from objective outcome data collection and underwent a telephone questionnaire evaluating subjective outcomes and RTP. In addition, $91.5 \%$ of the patients were involved in some sport before injury, with only $9.3 \%$ at a professional level.

At the time of surgery, in $86.4 \%$ of the cases, the lesion was defined as chronic ( $>3$ months from injury). In $64.2 \%$ of the patients, a BPTB graft was used, whereas in the remaining cases, a $\mathrm{QH}$ was used. In $40.3 \%$ of the cases, an associated procedure was performed: meniscectomy in $62 \%$, meniscal repair in $2.8 \%$, and cartilage procedures in $14.1 \%$. The postoperative rehabilitation was completed by $97.7 \%$ of the patients, with an average length of 3.8 months (SD \pm 2.1 months; range: $1-6$ months). In addition, $54.5 \%$ of the patients were involved at the end of the rehabilitation program in an OFR phase, consisting of a more sport-specific training to increase the athletes' confidence. The criteria to progress to this phase of rehabilitation were no ligament instability, no giving-way episodes during the preceding phases, minimal pain (visual analog scale $<3$ out of 10 ), absence or minimal effusion (grade 0 or $0 / 1+$ ), complete or nearly complete range of motion (ROM) (full extension, $<10^{\circ}$ flexion deficit vs. contralateral limb), and an isokinetic maximal peak torque deficit of less than $20 \%$ between limbs. ${ }^{16}$

Objective evaluation was available for 116 patients who returned to the clinic for follow-up. According to the IKDC knee evaluation form, $96.6 \%$ of the patients were graded as normal or nearly normal. Regarding knee instability, $30.2 \%$ of the patients had a positive pivot shift test, but only $2.6 \%$ of these cases had a clunk or a gross clunk. In $18.9 \%$ of the patients, the anteroposterior translation (measured with the KT-1000) was greater than $2 \mathrm{~mm}$ compared with the contralateral knee, but only $6 \%$ of these patients had a difference greater than $5 \mathrm{~mm}$, and $44.7 \%$ of the patients complained about increasing of anterior compartment crepitus compared with the preoperative setting.

At the multiple logistic regression analysis, different variables correlated with the objective outcomes were identified. Beginning of the rehabilitation later than 1 month after surgery was related to a lower total IKDC (odds ratio $[\mathrm{OR}]=2.75$; 95\% confidence interval $[\mathrm{CI}]=1.12-6.76)$. On the contrary, performing an OFR phase was related to a better total IKDC $(\mathrm{OR}=0.26 ; 95 \% \mathrm{CI}=0.11-0.61)$. Considering the single items of the IKDC objective score, receiving a contralateral ACL-R or acute ACL-R ( $<3$ months from injury) and beginning the rehabilitation more than 1 month after surgery was associated with a positive postoperative pivot shift test $(\mathrm{OR}=19.61, \mathrm{OR}=4.03$, and $\mathrm{OR}=2.78$, respectively). Finally, receiving a $\mathrm{QH}$ graft was related to a lower probability of being affected by postoperative anterior compartment crepitus ( $\mathrm{OR}=0.34 ; 95 \% \mathrm{CI}=0.15-0.76)$. - Table 2 summarizes all the results of univariate and multiple logistic regressions.
All the subjective outcomes are summarized in - Table 3. In all the scores, there was a statistically significant improvement after ACL-R. At the logistic regression, having a previous surgery in the ipsilateral knee was associated with a worse Lysholm score ( $\mathrm{OR}=0.17 ; 95 \% \mathrm{CI}=0.04-0.74)$. On the contrary, being involved in an OFR phase of the rehabilitation was related to a better IKDC score (OR $=2.71 ; 95 \%$ $\mathrm{CI}=1.29-5.67$ ). - Table 4 summarizes all the results of the univariate and multiple logistic regressions.

At the final follow-up, $90.1 \%$ of the patients (145 out of 161 ) were actively participating in sports, with $57.9 \%$ of these returning to the same preinjury level. The main reasons for not returning at the same level of performance or not returning to sport at all were knee symptoms (36.7\%), personal reasons $(30.4 \%)$, or both $(29.1 \%)$. Within the personal reasons, the most relevant one was the fear of reinjury (kinesophobia, $85 \%$ of the patients). The ACL-RSI score was used to measure the influence of psychological components in RTP. In this case series, the average ACL-RSI was $67.3 \%$ (SD $\pm 24.8 \%$ ).

At the logistic regression, doing rehabilitation for more than 3 months was related to higher RTP (OR = 13.16; 95\% $\mathrm{CI}=2.21-78.44)$. Furthermore, having a lower ACL-RSI indicating a greater psychological involvement was associated with a lower RTP rate $(\mathrm{OR}=0.04 ; 95 \% \mathrm{CI}=0.01$ 0.02) (-Table 5). The average postoperative SPORTS score was 6.9 points (SD: 3.9 points), with $59.6 \%$ of the patients having a score of 9 or 10 (complete return to the preinjury level with or without pain). At the multiple regression analysis, similar to RTP, lower ACL-RSI was also related to lower SPORTS score $(\mathrm{OR}=0.18 ; 95 \% \mathrm{CI}=0.08-0.39)$, indicating an association between psychological factors and RTP at the same preinjury level. Furthermore, having poor subjective outcome (Lysholm score $<85$ points) was also related to lower SPORTS score (OR $=0.20$; 95\% CI $=0.07$ $0.59)$.

The regression model was also applied to evaluate the variables affecting the ACL-RSI score. Having a Lysholm score inferior to 85 points as well as a low total objective IKDC score were associated with a low ACL-RSI and, consequently, to a high psychological involvement in RTP $(\mathrm{OR}=0.15,95 \%$ $\mathrm{CI}=0.05-0.47$; and $\mathrm{OR}=0.31,95 \% \mathrm{CI}=0.12-0.77$, respectively). No other variables were significantly correlated with the ACL-RSI score.

No major complications were detected, such as superficial/deep infection and thrombotic events. Forty-three patients suffered a minor complication (23.8\%), including fever (12 patients) and hemarthrosis (31 patients). Six patients underwent subsequent surgery at an average of 16.8 months ( $\mathrm{SD} \pm 12.5$ months) after ACL-R, including five arthroscopies (cartilage procedures or meniscectomy) and one hardware removal. Three patients underwent revision ACL-R at a mean of 14.6 months after surgery $(S D \pm 13.1$ months), with a failure rate of $3.4 \%$. The cumulative survivorship was $93.6 \%$ at 66.2 months ( $\mathrm{SD} \pm 4.4 \%$ ). No variables were identified as risk or protective factors toward failure at the regression analysis, including graft choice or rehabilitation-related variables. 


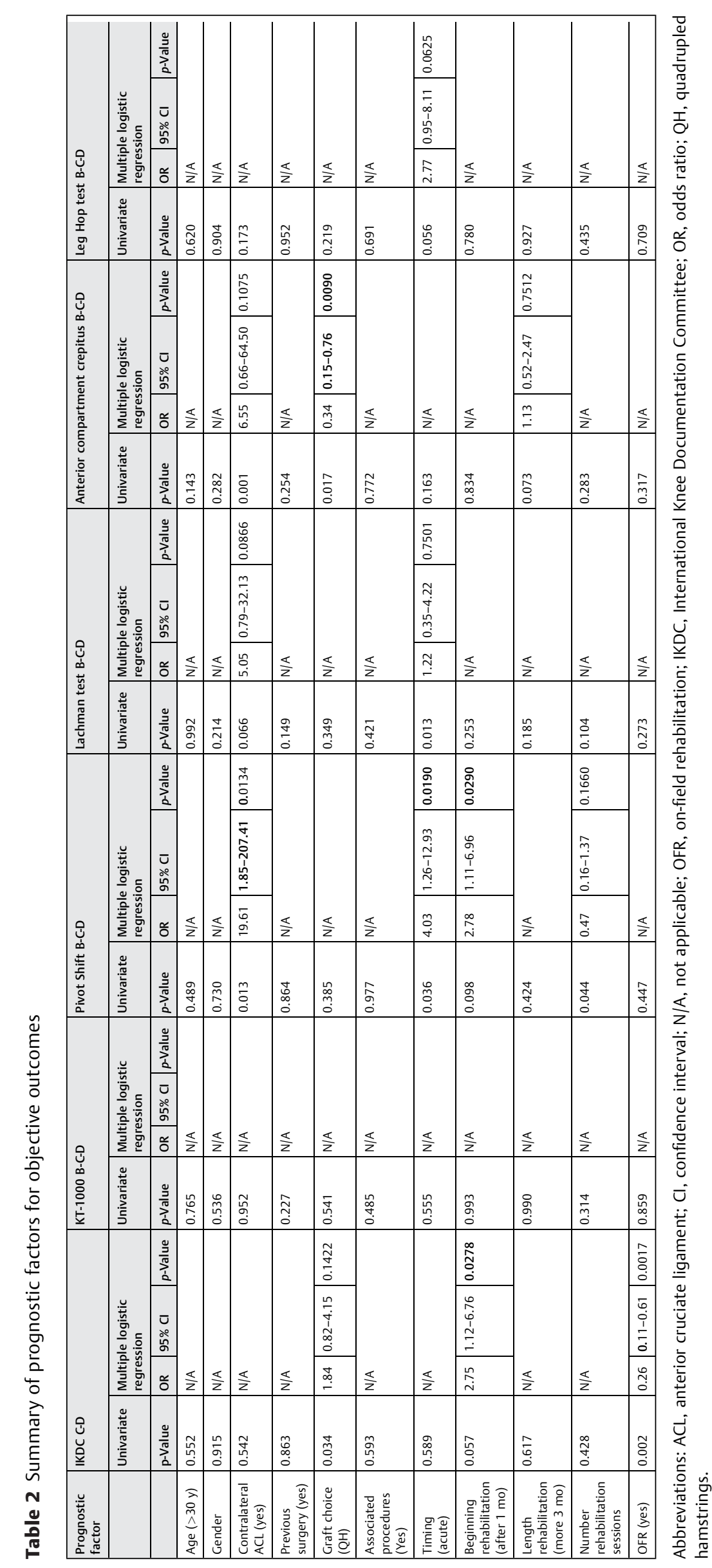


Table 3 Summary of subjective outcomes

\begin{tabular}{|l|l|l|l|}
\hline Subjective score & Preoperative score (SD) & Postoperative score (SD) & $p$-Value \\
\hline Lysholm & $76(S D \pm 13.7)$ & $91.1(S D \pm 12.1)$ & $p<0.0001$ \\
\hline Satisfaction & Not applicable & $81.1 \%(S D \pm 16.9 \%)$ & Not applicable \\
\hline KOOS & & & $p<0.0001$ \\
\hline Pain & $79.4(S D \pm 14)$ & $90.9(S D \pm 12.8)$ & $p=0.0361$ \\
\hline Symptoms & $86.3(S D \pm 12.7)$ & $87.3(S D \pm 14.2)$ & $p<0.0001$ \\
\hline Daily living & $88.8(S D \pm 9.5)$ & $97(S D \pm 23.1)$ & $p<0.0001$ \\
\hline Sport & $27.6(S D \pm 14.5)$ & $81.7(S D \pm 7.9)$ & $p<0.0001$ \\
\hline Quality of life & $34.9(S D \pm 10.7)$ & $77.8(S D \pm 23)$ & $p<0.0001$ \\
\hline IKDC & $41.3(S D \pm 10.1)$ & $83.2(S D \pm 16.2)$ & \\
\hline
\end{tabular}

Abbreviations: IKDC, International Knee Documentation Committee; KOOS, Knee Injury and Osteoarthritis Outcome Score; SD, standard deviation.

\section{Discussion}

This is a retrospective study on 176 ACL-Rs performed using the transtibial technique. Interestingly, there was a prevalence of male patients, in contrast with the literature, reporting a threefold increased risk for $\mathrm{ACL}$ rupture in female athletes. ${ }^{37}$ Good objective and subjective outcomes resulted from this study, both with BPTB and QH grafts, similar to the existing literature. $^{38}$

The most important finding in this study is the relationship between rehabilitation, subjective and objective outcomes, and RTP. Late rehabilitation beginning ( 1 month after surgery) was correlated with both worse total objective IKDC score $(\mathrm{OR}=2.75)$ and positive pivot-shift test $(\mathrm{OR}=2.78)$. This is probably related to the role of proprioception in knee stability and biomechanics. ${ }^{39}$ Furthermore, in the early phase of the rehabilitation, the strength of the graft is not optimal, and different exercises, such as isometric, isotonic, and isokinetic exercises, can improve graft strength without affect graft integrity. ${ }^{40}$ The most significant association was found between length of the rehabilitation and RTP, with patients involved in rehabilitation for more than 3 months having the higher chance for RTP $(O R=13.16)$. These results are consistent with the literature, which confirmed the increased rate of RTP in patients highly compliant with the rehabilitation program. ${ }^{5,41,42}$ Another important issue is the presence of an OFR phase in the rehabilitation program. In this study, being involved in an OFR phase resulted in better IKDC objective and subjective score $(\mathrm{OR}=0.26$ and $\mathrm{OR}$ $=2.71$, respectively). The relationship between postoperative rehabilitation program and subjective outcomes following ACL-R was previously demonstrated by other authors. Particularly, fully compliant patients with a supervised physical therapy program were demonstrated to have better knee function. ${ }^{42}$ Furthermore, Della Villa et al reported an improvement in the subjective outcome before and after the OFR phase of rehabilitation, concluding that a standardized, medically supervised OFR program may help in obtaining complete functional recovery after ACL-R. ${ }^{16}$

The second finding of this study was related to RTP rate and the relationship between outcomes and psychological involvement in RTP, measured with the ACL-RSI score. ${ }^{14}$ In our series, $90.1 \%$ of the patients returned to some sports activity at the final follow-up, but only $57.9 \%$ of those returned at the same preinjury activity level. These results are consistent with the literature. ${ }^{3,4,43}$ For patients not returning to sport, the two main reasons were knee symptoms (36.7\%) or personal reasons (30.4\%). In the latter case, $85 \%$ of the patients reported the fear of reinjury (kinesophobia) as the main reason. These findings are consistent with those reported by Flanigan et al, who concluded that fear of reinjury was cited by half of the patients who did not return to sports. ${ }^{11}$ As previously demonstrated by other authors, ${ }^{15,17,44}$ also in this study, a low ACL-RSI indicated a great psychological involvement and was associated with a lower RTP rate $(\mathrm{OR}=0.04)$. Furthermore, low ACL-RSI score as well as low Lysholm score were associated with low SPORTS score ( $O R=0.18$ and $O R=0.20$, respectively). The association between ACL-RSI and return to sport is confirmed by other studies. Particularly, Langford et al concluded that patients who did return to sport had a better ACL-RSI 6 months after surgery. ${ }^{45}$

In this study, both high Lysholm and IKDC objective scores were related to low psychological impairment $(\mathrm{OR}=0.15$ and $\mathrm{OR}=0.31$, respectively). In a recent study, Lentz et al confirmed that patients who were unable to return to preinjury sport levels were characterized by pain-related fear of reinjury, quadriceps weakness, and low IKDC score. ${ }^{12}$

Several authors previously evaluated the patient- or surgery-related factors associated with both subjective and objective outcomes. De Valk et al, in their meta-analysis, concluded that male gender, younger age, reconstruction within 3 months after injury, and high baseline activity level contribute to better functional outcomes. On the contrary, smoking, high body mass index, quadriceps weakness, and ROM deficit negatively affect the outcome. ${ }^{41}$ Other authors described obesity, smoking, cartilage degeneration, and some psychological factors as predictive of ACL-R outcomes. ${ }^{46}$ In our series, some surgery-related were associated with objective outcomes. Having contralateral ACL-Rs as well as an acute ACL-Rs were related to postoperative pivot shift $(\mathrm{OR}=19.61$ and $\mathrm{OR}=4.03$, respectively). This association 


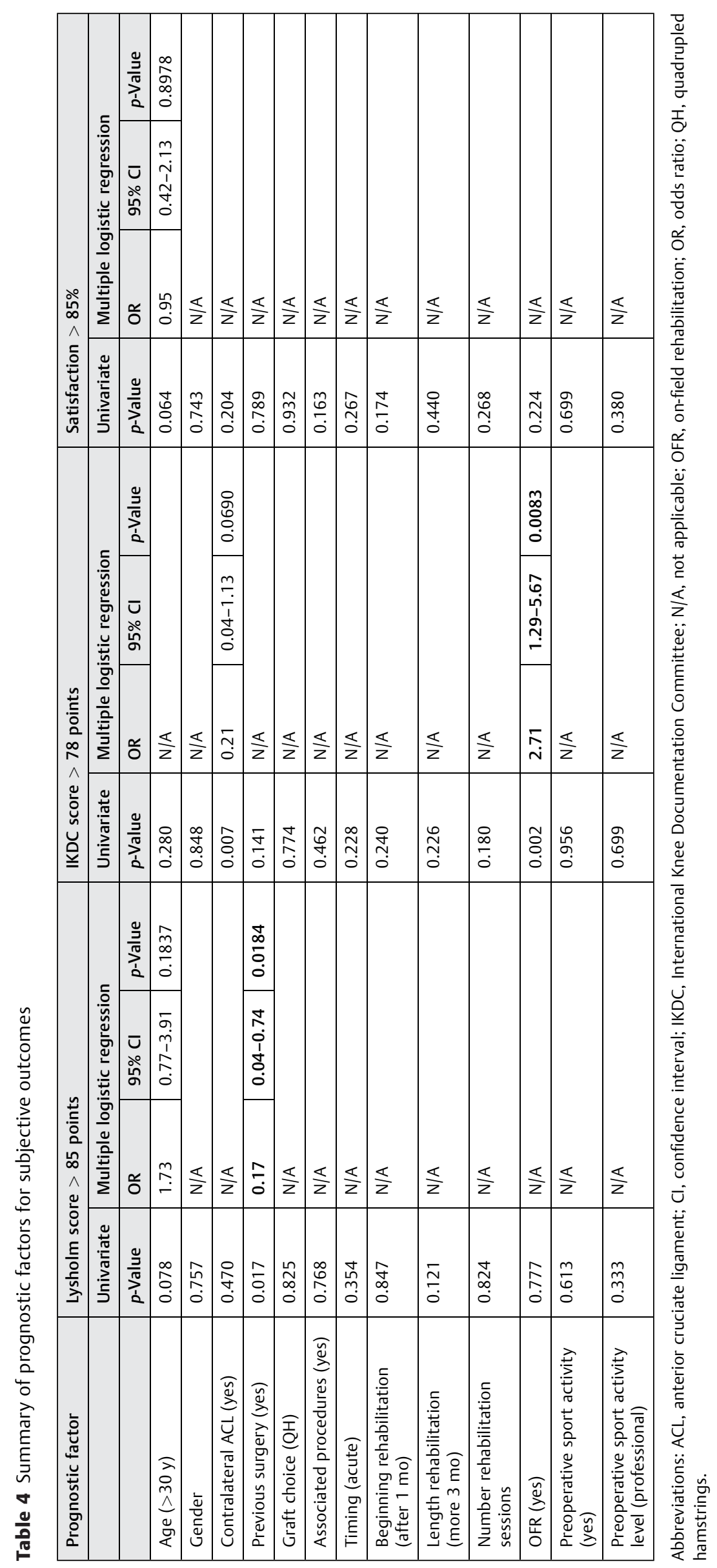




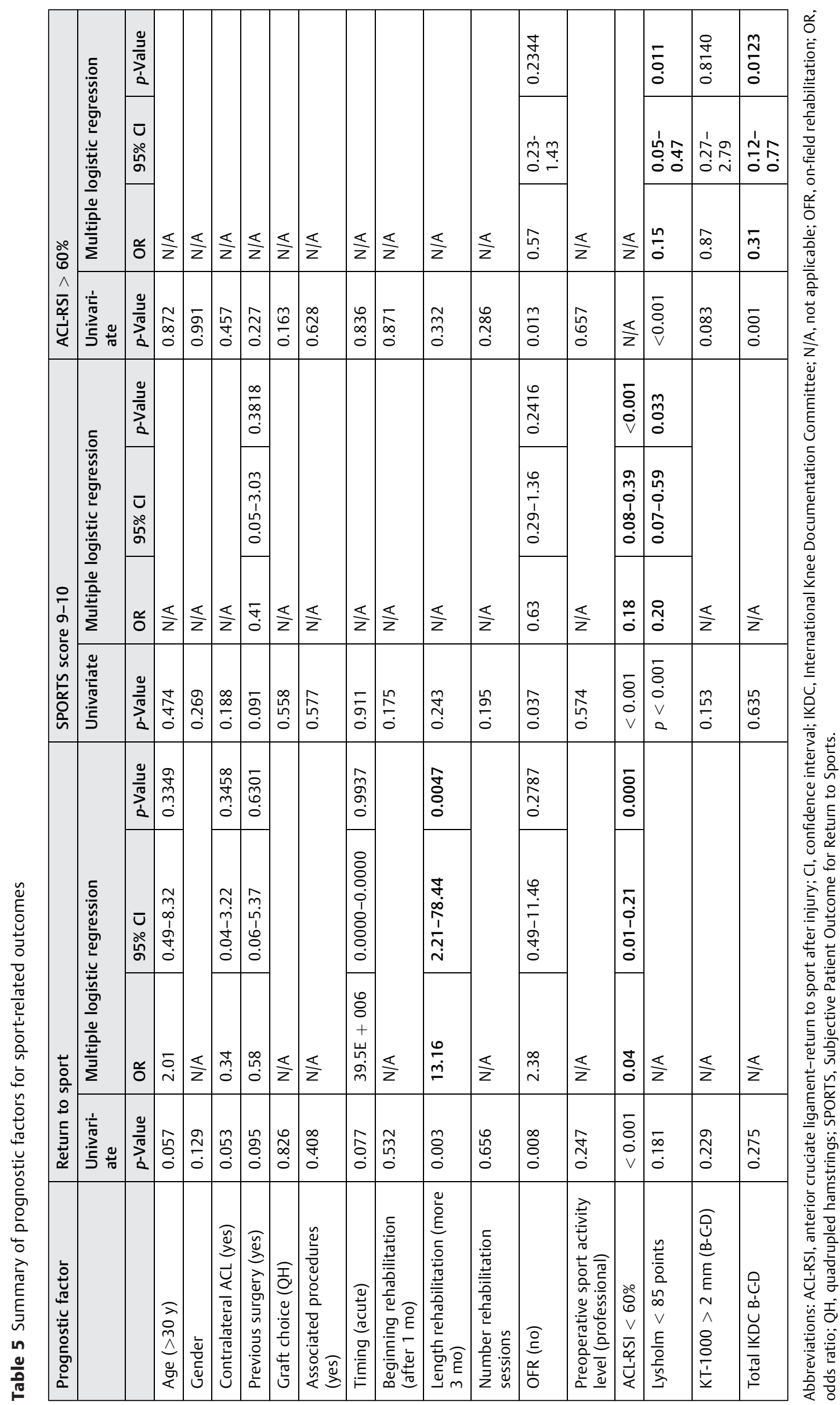


was not clearly understood, but it may be related to some tibial anatomical features, such as posteroinferior tibial slope and small tibial size, as well as undetected associated lesions. ${ }^{47}$ Furthermore, QH graft was related to a lower incidence of postoperative anterior crepitus. This finding is supported by previous studies comparing anterior knee pain between BPTB and $\mathrm{QH}$ grafts. ${ }^{38,48}$

The main limitation of this study is its retrospective nature. The variability in surgical procedure and postoperative protocols may affect the outcomes, and this is another limitation. To reduce this potential bias, these variables were included in the regression model. Furthermore, $34.1 \%$ of the patients did not return for the clinical follow-up. These patients underwent only a subjective telephonic evaluation and were excluded from the objective ones. However, it did not affect the statistical analysis because these patients were excluded from the logistic regression. Eventually, isokinetic and functional tests were not included in the statistical analysis to evaluate possible associations with subjective or objective outcomes since they were both considered as mandatory in allowing patients for RTP. Furthermore, different authors previously demonstrated the association between isokinetic quadriceps strength and outcomes after ACL-R. ${ }^{49}$

In conclusion, good objective and subjective outcomes were obtained in this case series, with $90.1 \%$ of RTP and $57.9 \%$ of the patients returning to the same preinjury activity level after ACL-R. Beginning of rehabilitation 1 month after surgery and receiving an acute ACL-R or a contralateral ACL-R negatively influenced objective outcomes (total IKDC score or positive pivot shift). The rehabilitation protocol was the most important factor affecting both subjective outcomes and return to sport. The role of psychological factors and OFR was confirmed by this study. Performing an OFR was associated with better subjective outcomes. Furthermore, psychological impairment, measured with the ACL-RSI score, was associated with both lower RTP and lower level of activity. This association suggested to include OFR phase and questionnaire evaluating the psychological readiness in the evaluation of return to sport after ACL-R.

\section{Conflict of Interest}

None.

\section{References}

1 Mall NA, Chalmers PN, Moric M, et al. Incidence and trends of anterior cruciate ligament reconstruction in the United States. Am J Sports Med 2014;42(10):2363-2370

2 Samitier G, Marcano AI, Alentorn-Geli E, Cugat R, Farmer KW, Moser MW. Failure of anterior cruciate ligament reconstruction. Arch Bone Jt Surg 2015;3(04):220-240

3 Ardern CL, Taylor NF, Feller JA, Webster KE. Return-to-sport outcomes at 2 to 7 years after anterior cruciate ligament reconstruction surgery. Am J Sports Med 2012;40(01):41-48

4 McCullough KA, Phelps KD, Spindler KP, et al; MOON Group. Return to high school- and college-level football after anterior cruciate ligament reconstruction: a Multicenter Orthopaedic Outcomes Network (MOON) cohort study. Am J Sports Med 2012;40(11): 2523-2529

5 Ardern CL, Taylor NF, Feller JA, Webster KE. Fifty-five per cent return to competitive sport following anterior cruciate ligament reconstruction surgery: an updated systematic review and metaanalysis including aspects of physical functioning and contextual factors. Br J Sports Med 2014;48(21):1543-1552

6 Nwachukwu BU, Voleti PB, Berkanish P, et al. Return to play and patient satisfaction after ACL reconstruction: study with minimum 2-year follow-up. J Bone Joint Surg Am 2017;99(09): $720-725$

7 Lai CCH, Ardern CL, Feller JA, Webster KE. Eighty-three per cent of elite athletes return to preinjury sport after anterior cruciate ligament reconstruction: a systematic review with meta-analysis of return to sport rates, graft rupture rates and performance outcomes. Br J Sports Med 2018;52(02):128-138

8 Mohtadi NG, Chan DS. Return to sport-specific performance after primary anterior cruciate ligament reconstruction: a systematic review. Am J Sports Med 2017. Doi: 10.1177/0363546517732541

9 McGrath TM, Waddington G, Scarvell JM, et al. An ecological study of anterior cruciate ligament reconstruction, part 2: functional performance tests correlate with return-to-sport outcomes. Orthop J Sports Med 2017;5(02):2325967116688443

10 Ardern CL, Taylor NF, Feller JA, Whitehead TS, Webster KE. Psychological responses matter in returning to preinjury level of sport after anterior cruciate ligament reconstruction surgery. Am J Sports Med 2013;41(07):1549-1558

11 Flanigan DC, Everhart JS, Pedroza A, Smith T, Kaeding CC. Fear of reinjury (kinesiophobia) and persistent knee symptoms are common factors for lack of return to sport after anterior cruciate ligament reconstruction. Arthroscopy 2013;29(08):1322-1329

12 Lentz TA, Zeppieri G Jr, George SZ, et al. Comparison of physical impairment, functional, and psychosocial measures based on fear of reinjury/lack of confidence and return-to-sport status after ACL reconstruction. Am J Sports Med 2015;43(02): 345-353

13 Paterno MV, Flynn K, Thomas S, Schmitt LC. Self-reported fear predicts functional performance and second ACL injury after ACL reconstruction and return to sport: a pilot study. Sports Health 2017. Doi: $10.1177 / 1941738117745806$

14 Webster KE, Feller JA, Lambros C. Development and preliminary validation of a scale to measure the psychological impact of returning to sport following anterior cruciate ligament reconstruction surgery. Phys Ther Sport 2008;9(01):9-15

15 Müller U, Krüger-Franke M, Schmidt M, Rosemeyer B. Predictive parameters for return to pre-injury level of sport 6 months following anterior cruciate ligament reconstruction surgery. Knee Surg Sports Traumatol Arthrosc 2015;23(12):3623-3631

16 Della Villa S, Boldrini L, Ricci M, et al. clinical outcomes and return-to-sports participation of 50 soccer players after anterior cruciate ligament reconstruction through a sport-specific rehabilitation protocol. Sports Health 2012;4(01):17-24

17 Everhart JS, Best TM, Flanigan DC. Psychological predictors of anterior cruciate ligament reconstruction outcomes: a systematic review. Knee Surg Sports Traumatol Arthrosc 2015;23(03): 752-762

18 Krych AJ, Woodcock JA, Morgan JA, Levy BA, Stuart MJ, Dahm DL. Factors associated with excellent 6-month functional and isokinetic test results following ACL reconstruction. Knee Surg Sports Traumatol Arthrosc 2015;23(04):1053-1059

19 Jones MH, Spindler KP. Risk factors for radiographic joint space narrowing and patient reported outcomes of post-traumatic osteoarthritis after ACL reconstruction: data from the MOON cohort. J Orthop Res 2017;35(07):1366-1374

20 Cox CL, Huston LJ, Dunn WR, et al. Are articular cartilage lesions and meniscus tears predictive of IKDC, KOOS, and Marx activity level outcomes after anterior cruciate ligament reconstruction? A 6 -year multicenter cohort study. Am J Sports Med 2014;42(05): 1058-1067

21 Abrams GDHJ, Harris JD, Gupta AK, et al. Functional performance testing after anterior cruciate ligament reconstruction: a systematic review. Orthop J Sports Med 2014;2(01):2325967113518305 
22 Xergia SA, Pappas E, Georgoulis AD. Association of the single-limb hop test with isokinetic, kinematic, and kinetic asymmetries in patients after anterior cruciate ligament reconstruction. Sports Health 2015;7(03):217-223

23 Logerstedt D, Grindem H, Lynch A, et al. Single-legged hop tests as predictors of self-reported knee function after anterior cruciate ligament reconstruction: the Delaware-Oslo ACL cohort study. Am J Sports Med 2012;40(10):2348-2356

24 Gokeler A, Welling W, Zaffagnini S, Seil R, Padua D. Development of a test battery to enhance safe return to sports after anterior cruciate ligament reconstruction. Knee Surg Sports Traumatol Arthrosc 2017;25(01):192-199

25 Irrgang JJ, Anderson AF, Boland AL, et al. Development and validation of the International Knee Documentation Committee subjective knee form. Am J Sports Med 2001;29(05):600-613

26 Padua R, Bondi R, Ceccarelli E, et al. Italian version of the International Knee Documentation Committee Subjective Knee Form: cross-cultural adaptation and validation. Arthroscopy 2004;20(08):819-823

27 Briggs KK, Lysholm J, Tegner Y, Rodkey WG, Kocher MS, Steadman JR. The reliability, validity, and responsiveness of the Lysholm score and Tegner activity scale for anterior cruciate ligament injuries of the knee: 25 years later. Am J Sports Med 2009;37(05): 890-897

28 Collins NJ, Misra D, Felson DT, Crossley KM, Roos EM. Measures of knee function: International Knee Documentation Committee (IKDC) Subjective Knee Evaluation Form, Knee Injury and Osteoarthritis Outcome Score (KOOS), Knee Injury and Osteoarthritis Outcome Score Physical Function Short Form (KOOS-PS), Knee Outcome Survey Activities of Daily Living Scale (KOS-ADL), Lysholm Knee Scoring Scale, Oxford Knee Score (OKS), Western Ontario and McMaster Universities Osteoarthritis Index (WOMAC), Activity Rating Scale (ARS), and Tegner Activity Score (TAS). Arthritis Care Res (Hoboken) 2011;63(Suppl 11):S208-S228

29 Higgins LD, Taylor MK, Park D, et al; International Knee Documentation Committee. Reliability and validity of the International Knee Documentation Committee (IKDC) Subjective Knee Form. Joint Bone Spine 2007;74(06):594-599

30 Monticone M, Ferrante S, Salvaderi S, et al. Development of the Italian version of the knee injury and osteoarthritis outcome score for patients with knee injuries: cross-cultural adaptation, dimensionality, reliability, and validity. Osteoarthritis Cartilage 2012;20 (04):330-335

31 Roos EM, Roos HP, Lohmander LS, Ekdahl C, Beynnon BD. Knee Injury and Osteoarthritis Outcome Score (KOOS)-development of a self-administered outcome measure. J Orthop Sports Phys Ther 1998;28(02):88-96

32 Rockborn P, Gillquist J. Outcome of arthroscopic meniscectomy. A 13-year physical and radiographic follow-up of 43 patients under 23 years of age. Acta Orthop Scand 1995;66(02):113-117

33 Cole BJ, Cotter EJ, Wang KC, Davey A. Patient understanding, expectations, outcomes, and satisfaction regarding anterior cruciate ligament injuries and surgical management. Arthroscopy 2017;33(05):1092-1096

34 Hambly K, Griva K. IKDC or KOOS: which one captures symptoms and disabilities most important to patients who have undergone initial anterior cruciate ligament reconstruction? Am J Sports Med 2010;38(07):1395-1404

35 Johnson DS, Smith RB. Outcome measurement in the ACL deficient knee-what's the score? Knee 2001;8(01):51-57

36 Blonna D, Castoldi F, Delicio D, et al. Validity and reliability of the SPORTS score. Knee Surg Sports Traumatol Arthrosc 2012;20(02): 356-360

37 Prodromos CC, Han Y, Rogowski J, Joyce B, Shi K. A meta-analysis of the incidence of anterior cruciate ligament tears as a function of gender, sport, and a knee injury-reduction regimen. Arthroscopy 2007;23(12):1320-1325

38 Kautzner J, Kos P, Hanus M, Trc T, Havlas V. A comparison of ACL reconstruction using patellar tendon versus hamstring autograft in female patients: a prospective randomised study. Int Orthop 2015;39(01):125-130

39 Saka T. Principles of postoperative anterior cruciate ligament rehabilitation. World J Orthop 2014;5(04):450-459

40 van Grinsven S, van Cingel RE, Holla CJ, van Loon CJ. Evidencebased rehabilitation following anterior cruciate ligament reconstruction. Knee Surg Sports Traumatol Arthrosc 2010;18(08): 1128-1144

41 de Valk EJ, Moen MH, Winters M, Bakker EW, Tamminga R, van der Hoeven H. Preoperative patient and injury factors of successful rehabilitation after anterior cruciate ligament reconstruction with single-bundle techniques. Arthroscopy 2013;29(11):1879-1895

42 Han F, Banerjee A, Shen L, Krishna L. Increased compliance with supervised rehabilitation improves functional outcome and return to sport after anterior cruciate ligament reconstruction in recreational athletes. Orthop J Sports Med 2015;3(12): 2325967115620770

43 Ardern CL, Webster KE, Taylor NF, Feller JA. Return to sport following anterior cruciate ligament reconstruction surgery: a systematic review and meta-analysis of the state of play. $\mathrm{Br} \mathrm{J}$ Sports Med 2011;45(07):596-606

44 Ardern CL, Österberg A, Tagesson S, Gauffin H, Webster KE, Kvist J. The impact of psychological readiness to return to sport and recreational activities after anterior cruciate ligament reconstruction. Br J Sports Med 2014;48(22):1613-1619

45 Langford JL, Webster KE, Feller JA. A prospective longitudinal study to assess psychological changes following anterior cruciate ligament reconstruction surgery. Br J Sports Med 2009;43(05): 377-381

46 Kowalchuk DA, Harner CD, Fu FH, Irrgang JJ. Prediction of patientreported outcome after single-bundle anterior cruciate ligament reconstruction. Arthroscopy 2009;25(05):457-463

47 Tanaka M, Vyas D, Moloney G, Bedi A, Pearle AD, Musahl V. What does it take to have a high-grade pivot shift? Knee Surg Sports Traumatol Arthrosc 2012;20(04):737-742

48 Lidén M, Ejerhed L, Sernert N, Laxdal G, Kartus J. Patellar tendon or semitendinosus tendon autografts for anterior cruciate ligament reconstruction: a prospective, randomized study with a 7-year follow-up. Am J Sports Med 2007;35(05):740-748

49 Pua YH, Ho JY, Chan SA, Khoo SJ, Chong HC. Associations of isokinetic and isotonic knee strength with knee function and activity level after anterior cruciate ligament reconstruction: a prospective cohort study. Knee 2017;24(05):1067-1074 